\title{
Features of Using the Cryptocurrency
}

\author{
Ekaterina Mikhailovna Taran ${ }^{1}$, Irina Pavlovna Salmanova ${ }^{1}$, Elena Viktorovna Dokukina ${ }^{1}$, Margarita Arkadevna \\ Menshikova $^{1} \&$ Nelly Zinurovna Skudareva ${ }^{1}$ \\ ${ }^{1}$ Financial and Technological Academy, Russian Federation \\ Correspondence: Irina Pavlovna Salmanova, Gagarin street, 42, Korolev, 141070, Moscow region, Russian \\ Federation.
}

Received: December 28, 2014 Accepted: March 23, 2015 Online Published: May 22, 2015

doi:10.5539/ass.v11n14p330 URL: http://dx.doi.org/10.5539/ass.v11n14p330

\begin{abstract}
The article highlights the issues of emergence and existence of cryptocurrency. Exploring online space, you can select the most popular existing electronic currency which is bitcoin (Bitcoin). The article analyzed the pros and cons and the legality of these "money" in Russia and abroad. Some people believe the money that exist in the online space are simply "cheating", and therefore it is not worth to trust them, but others say that this currency will proceed the future of electronic payments.
\end{abstract}

Keywords: Cryptocurrency, Bitcoin, money, mining, electronic currency

\section{Introduction}

Cryptocurrency is money in the form of numbers. It is made not from paper, it is not the precious coins, but cryptocurrency is money in the form of numbers that can be stored in a file on a personal computer. But how do you know where are these numbers? They are generated, calculated by all sorts of complicated formulas. They are forgery. In other words, Bitcoins are some difficult to count numbers, which at the end of the calculations take the form of money. (FL "About Central Bank RF (Bank of Russia)", 2013).

Essentially anything can be money. To do this requires the consent of at least two sides. If you take and tear off leaves from a tree and other side says that it is ready to take the same leaves to be paid for their labor or services, and you say that you are ready to accept them as their own, then you can pay with leaves. This will be our money. These are just necessary conditions. Bitcoins and creators sharing their views once agreed to consider Bitcoin money. They were sided by new enthusiasts. It got to the point that Bitcoins could be paid for services in online space. However, bread still cannot be bought by Bitcoins, but who knows what will be in the future.

\section{Method}

\subsection{The Origin of the Bitcoin Payment System}

Over the past six months the Bitcoin payment system attracted a lot of attention. The exchange rate of virtual coins sharply reached from $\$ 200$ per coin in September to $\$ 1,300$ by the end of November, 2013. However, in early 2014 after the holidays the rate stabilized and currently it fluctuates in a narrow range between 900 and 1000 dollars (Agarkin, 2011). Proponents argue Bitcoin to be the cryptocurrency which has many properties that can make it an ideal currency for major customers and vendors. For example, Bitcoin has high liquidity, low transaction costs, it can be used to send instant online payments and micropayments (Alekseev et al., 2012). Monitoring the situation of handling the so-called virtual currencies (cryptocurrency) shows a growing interest to them, including the possibility of crime money laundering.

We will try to figure out how this is constructed and consider the interesting facts about Bitcoin.

The mystery still remains, who is involved in "the birth" of Bitcoin. As we can find in press, the author of the virtual currency is the programmer Satoshi Nakamoto. According to some sources, in 2008 he single-handedly, (and according to other sources, - with a group of associates working under his pseudonym Satoshi) developed the source code of the first "e-wallet" (electronic wallet) and made it available to all. A year later, Nakamoto has left the project and transferred all its powers of the subsequent development to Gavin Andresen. Satoshi Nakamoto still denies the fact of their relationship to the project. In contrast to the "paper" money issued by governments of all countries, Bitcoins do not have any control of the regulator. Currency has no administrator, and therefore has full autonomy, so nobody has the right to ban its use. Bitcoin is a set of numbers, which is 
transmitted from one computer to another and the transaction's information is stored in the form of a cipher for all participants in the monetary system. That's why Bitcoins have been called "decentralized cryptocurrency". There is no single centralized location responsible for the "issue" of virtual money. So it is the second characteristic feature of Bitcoin. Users of the "mine" coin system need only the video card in their PC system units.

\subsection{Features of Bitcoin Currency}

There are markets, so called "Bitcoin Exchange", which allow people to buy or sell Bitcoin using different currencies. Mt. Gox Exchange is the largest exchange market of Bitcoin. People can send Bitcoin each other through mobile applications or computers. This is like sending cash in a digital form. People complete "collecting" Bitcoins using computers to solve complex mathematical problems. Thus Bitcoin is created (Belov, 2010).

"Mining" is getting money from almost empty, it is a slow process that requires enormous computing capabilities, as well as electricity costs. The existence algorithm of Bitcoin currency involves one very important point. There is a limit of the total number of coins. It should not exceed 21 million. After reaching this limit; emissions will stop. Since 2009, about 12 million was released, that is near the half. It is predicted that the resource may be exhausted by 2150, taking into account annual increase of the production process complexity (Virtual Gold standard. URL: forbes.ru/tehno/internet-i-telekommunikatsii/67492-virtualnyi-zolotoi-standart. Date Views 30.03.2014).

System is made vulnerable by its legal status. Everywhere it has a different explanation. In early December 2013 the People's Bank of China put its departments under a ban on transactions carried out in Bitcoins. The Central Bank of France calls this cryptocurrency speculative instruments prone to high risk. Thailand criticize the Bitcoin too, its National Bank has not recognized an independence of virtual currency. In Germany the situation is more positive. There Bitcoin was taken and it fell under the definition of private money.

\subsection{Abilities of Bitcoin Currency}

Purchase of electronics, clothes, books, food and other items provided on the Internet can be made by Bitcoin payments. Number of exchange points, where electronic money is converted into normal money is increasing constantly (Bitcoin: An Innovative Alternative Digital Currency. Social science research network. URL papers.ssrn.com/sol3/papers.cfm?abstract_id=1817857, Date Views 01.01.2015).

The world's first ATM machine that allows you one to convert Bitcoins into dollars and vice versa appeared in Canada in October 2013. Robocoin Apparatus certifies the identity of the person on the basis of handprints. Exchanges worth about $\$ 3,000$ can be produced per day. Although Bitcoin is electronic currency, it like all sorts of currency it is susceptible to theft (Babina \& Bashirova, 2012). Bitcoins is not just a single "cryptocurrency", but it is the first one, which is widely accepted. There are also other currencies, such as Litecoin, which may be produced much faster, Namecoin and dozens of others (Berezina M.P., Business and banks. \#22, 2012). First of all, attractiveness of Bitcoin is determined by its anonymity. This is the most expensive currency, while it is open enough and at the same time is absolutely opaque. This is the paradox of this cryptocurrency. It is no coincidence that Bitcoins are popular in criminal structures in the field of trafficking in arms, drugs and even assassinations.

For example, there was a SilkRoad online store selling drugs, which functioned in the anonymous network Tor, part of the Internet, which cannot be detected by search engines. Besides psychotropic substances (including LSD, marijuana, and heroin), site offers also pornographic material and banned books. Ross William Ulbricht, the resource owner, was detained and his servers with the stored Bitcoins were withdrawn. All purchases were paid by using Bitcoin.

A year ago, Assassination Market (market of murders or murder attempts) also appeared on the Tor network's. Its visitors are encouraged to invest in Bitcoins in killing public persons and politicians. Customer before executing the order must make a donation of 1 Bitcoin to the killer encrypting it dates alleged assassination attempt. After executing the killer will be listed other Bitcoins and founders resource receive $1 \%$ commission (Berezina M.P., Business and banks. \#22, 2012).

One of the UK residents, Briton, "extracted" 7500 Bitcoins at a time when it was very easy to do. After he accidentally spilled tea on a laptop he threw the burned computer in the trash. Briton greatly regretted about his decision when the rate of e-currency rose to $\$ 1,000$ what could make him a millionaire. He had not succeeded to find dumped "source of wealth" in a landfill. Recently the decision was made by the Financial Supervision Commission of Taiwan to prohibit the use of Bitcoin ATM explaining that Bitcoin is false currency which 
should not be used by people or banks for payments. Other countries with currency control are Brazil, Egypt, Iceland, North Korea, Russia, South Africa, India and Argentina (Bunkina \&Semenov, 2012).

A few years ago Bitcoin has not been used for payments. In 2011, an American from Florida decided to try to pay by "cryptocurrency", giving one of the Internet forum members 10,000 Bitcoins ( $\$ 25$ at that time) in exchange for the delivery of two pizzas. Now American's dinner is the most expensive in the history ( $\$ 8.5$ million).

Today, the Bitcoin is the most expensive currency. In 2009, the Norwegian student Peter X. wrote a scientific work devoted to unknown e-currency. For this purpose he purchased a few "coins", paying $\$ 25$. He made it and forgot. He recalled his purchase when he accidentally stumbled on a note about the record price hike of studied currency. It turned out that the total cost of purchased "coins" reached one million dollars. Bitcoin exchange rate is determined by supply and demand for it. Rates depend on the willingness of people to buy or sell coins. Why do people now want to buy Bitcoins? Apparently, enthusiasts still believe and hope that in the future there will be another jump in the cost of Bitcoin and the price will reach the record highest level.

\section{Results}

It is quite clear that Bitcoin has ceased not to be only a toy of programmers. Governments in developed countries are discussing what to do with e-currency, private business is active, but at the same time carefully experimenting with Bitcoins. Currently Bitcoin emerged from the shadows. The system rotates billions of real dollars most of which is criminal. But the most valuable currency in the world has more and more supporters among romantics who dream of a better radiant life. Furthermore, Bitcoin can now be used by decentralized company for international payments that was impossible previously. Doing business with consumers using Bitcoin is available in many countries all over the world. For example, the electronics retailer that accepts payments in Bitcoins, recently pointed out that during the last nine months he sold $\$ 300,000$ of goods to 40 countries. This includes countries such as Pakistan and Moldova, which were previously unavailable for American traders (Demidova \& Ibragimova, 2010).

An experiment was conducted to determine the locations in countries where Bitcoin is used. It lasted 101 days; a married couple from the United States took part in the experiment. They had to pay for all things just by virtual currency. The journey started from Utah to New York, then there was hop across the Atlantic to Stockholm, there were also Berlin and Singapore. All the time the family was paying for absolutely everything by Bitcoin including food in supermarkets, restaurants, clothing stores, etc. Most complex were searches of gas stations. Bitcoins was not accepted everywhere and they have to prove that it is indistinguishable from the real ones (Samoshkina, 2011). Not only virtual currency exchange rate grows, but a number of users as well. University of Nicosia in Cyprus accepts Bitcoin as tuition fee. Popular e-commerce platform Shopify added Bitcoin-payment option for their sales at the end of last year. Having a base of more than 70,000 online stores, the amount of goods purchased using Bitcoin has increased considerably (Таран \& Таран, 2014).

In Europe and America a number of places where it is possible to spend accumulated virtual money are constantly growing that of course is different from Russia. One of the most favorite places in the network for the lucky owners of digital currencies is gambling sites, such as online casino. Here you can quickly double or lose your capital (Redhed \& Hughes, 2010).

SatoshiDice today remains one of the most popular gambling sites. Members betting send digital money to one of the accounts and in return receive a payment based on the probability of the winning. Casino PeerBet is also widely known, where other Cryptocurrencies are accepted in addition to Bitcoin.

Bitcoins are perfect for online payment services, but it does not mean that the digital currency cannot be used to purchase real goods. There are a number of sites offering real tangible goods for Bitcoins, although they mainly accept payments via the Internet (URL: What is Cryptocurrency? https://7pay.in/crypto. Date Views 15.01.2015).

Bitcoinshop.us, for example, offers a wide range of products from air conditioners to watches. For those who wish to buy, prices are set in Bitcoins. One catch: the delivery is only to the residents of the continental part of the United States.

Memory Dealers supplies network equipment and memory cards for personal computers. This company trusted Bitcoin digital currency since its birth. CoinSpot provides you the addresses of the interesting local merchants. For example, Keystone Pet Place will satisfy all the needs of your pet. The Java Nomad will send you fresh coffee beans directly from Bali. Persian Shoes will sell you handmade shoes and bags from Iran. Some highly specialized local shops accept as payment only Bitcoins, and do not use the official currency. 
The good news is that around the world there are hundreds of small retail shops, where digital money is accepted (Pashkus, 2013).

\section{Discussing}

\subsection{Features of the Bitcoin Used as a mean of Payment}

In general, the process is started, the technology is widespread and it can no longer be ignored. Many people know about Bitcoin, and buying it is not a problem. But what should do with it? The meeting which has a strong name "Expert Group Meeting at the Interagency Working Group on combating economic crimes" was attended by representatives of the Prosecutor General of the Russian Federation, representatives of the Central Bank of the Russian Federation, the FSB and the Interior Ministry. The major question under discussion at a meeting was "cryptocurrency in Russia: to be or not to be". Just according to the title of the meeting it is clear that Bitcoin was considered as a negative phenomenon (Larichev, 2011).

The final conclusion of the meeting was that the distinguishing feature of Bitcoin as a means of settlement and accumulation is the lack of availability of real value. Its price is determined by speculative actions that entail a high risk of loss of value, and thus a violation of the rights of persons holding this currency.

According to the Art. 27 of the Federal Law "On the Central Bank of the Russian Federation" official currency of the Russian Federation is the ruble. Introduction on the territory of Russia other monetary units and issue of money substitutes is prohibited (URL: The Ministry of Finance intends to ban cryptocurrency. http://pronedra.ru/money/2014/10/06/minfin-kriptoovaluta/, Date Views 08.10.2014). The owners of cryptocurrency in Russia have rights to protect their interests in administrative proceedings.

Following the meeting it was decided to hold a series of measures aimed at preventing violations in the sphere of money circulation in the Russian Federation. Taking into account international experience, further areas of the work on the legal regulation of this sector were identified. Unfortunately, it is not known the origin of the activities that are planned. There is no content on this occasion (URL: What is Cryptocurrency? https://7pay.in/crypto. Date Views 15.01.2015). Presumably, using of cryptocurrency in Russia will be strictly limited. Internet users from Russia show the greatest interest in the new currency. Because of the lack of official position of Russian financial regulators, the use of Bitcoins for its intended purpose (payment for goods and services) is very tentative. If a decision on the use of Bitcoin as a means of payment will be accepted, it is necessary to evaluate the opportunities and risks of the new currency (URL: The Ministry of Finance intends to ban cryptocurrency. http://pronedra.ru/money/2014/10/06/minfin-kriptoovaluta/, Date Views 08.10.2014).

\subsection{Supporters and Opponents of Bitcoins}

The whole world is divided into two groups: those who approve Bitcoins, and those who want to ban them. However, there is a clear pattern: cryptocurrency is supported by the country in which its own currency is stable and strong, but a country with a weak currency and large trade flows, as China, try to ban Bitcoins. But the attempt to limit Bitcoins now is clear: Bitcoins had a very significant use.

Whilst one country (such as e.g. Australia) fully uses cryptocurrency, the other countries are quite skeptical. A prime example is Russia.

Russian authorities have prepared a bill aimed at restricting access of Bitcoins - the most popular of the existing Cryptocurrencies. In particular, the Ministry of Finance proposes to restrain people wishing to use cryptocurrency by severe penalties.

Not so long ago, Microsoft Chairman Bill Gates also spoke in support of Bitcoins, but he found that the technology needs to be expanded. According to him, Bitcoin will not get mass distribution because of its anonymity, since the authorities will always assume this payment system as a mean for white-washing and terrorist instrument.

Operations with Bitcoins are now held in the United States, Singapore, Bulgaria. Investors believe that the currency may be the most promising in India and South-East Asia.

But despite the sharp reaction across the world, there are countries that use this "currency" to the maximum extent. For example, residents of the Australian city of Launceston are building a closed economic system based on Bitcoin cryptocurrency. In the city with a population of 106 thousand people a business network will be established, where one can both earn and spend cryptocurrency that automatically exclude circulation of Australian dollars.

In addition, the city will develop tourism, attracting wealthy travelers to spend their savings in cryptocurrency in Launceston. 
According to the plan, the city must create their own government that will lead the taxation procedure in Bitcoin. Two of the twelve members of the city council have already approved this initiative.

Project Director, Adam Poulton commented potential Bitcoin: "Bitcoin cryptocurrency is used in all developed countries. Over the past 12 months, its total value increased to $\$ 20$ billion. Launceston's turn to appreciate the advantages of virtual money came".

First the virtual currency will be accepted by shops that accept digital payments. Bitcoins will be gradually taken by all traders of the city. Most of the cryptocurrency will remain within the city, in order to evaluate the advantages and disadvantages of Bitcoin-closed economy.

Today one can pay Bitcoins in major online stores in the US, such as Overstock and Newegg, buy property in London, a lot of different online services accept this currency. For Bitcoins you one can buy tickets ef for Air Baltic flights, to pay for a hotel on the Expedia online service site make purchases in App Store (Redhed \& Hughes, 2010).

In Russia Bitcoins payments are accepted by IT-bar in St. Petersburg, some points of fast food, Subway Killfish bars, and even hotels, in particular B\&B Hostel in Krasnoyarsk (Melnikov, 2012).

Bitcoin critics often accuse this currency of in instability of its rate. To date, the official rate of one Bitcoin is \$342.32. In January, one Bitcoin was over $\$ 800$. In December 2013 the rate reached the maximum level equal to $\$ 1,240$ per Bitcoin. After that its value has fallen twice due to the prohibition of the Chinese Central Bank to official financial institutions to conduct transactions in Bitcoins.

\subsection{Comparative Characteristics of Some Payment Systems}

From the perspective of e-commerce, using Bitcoin to pay for goods can be called a new payment system, such as WebMoney and Yandex-money. Each payment system should have an operator that defines the rules of the payment system and a license to conduct banking operations. Yet Bitcoin's operator in Russia does not exist. BitPay Company organizes provides acceptance of Bitcoin for online merchants but it is not the only way to organize the sales. BitPay cannot be called the operator of Bitcoin's payment system. Taking into account the low level of payments commission, we can assume that in the short term Bitcoin becomes popular e-currency in our country as for internal payments and international transfers (Larichev, 2011).

What are features that make Bitcoin is better than YandexMoney, Webmoney or QIWI? All of the above are the payment systems, not currencies. Payment system is a set of rules, procedures and technical infrastructure, providing the transition of the cost from one subject to another. Payment systems are a key part of modern monetary systems. Units in these payment systems are directly tied to one of the national currency. In addition, the systems themselves are controlled by companies that are going to have transfer fees and may terminate your account for any reason. Bitcoin is not controlled by anyone and is not tied to any currency (its exchange rate floated against other currencies, depending on supply and demand). It is best to think of Bitcoin as a digital gold - no one controls the gold itself, i.e., anyone can own and can get it, but it cannot be "printed" or change its properties in any way (Satoshi Nakamoto, 2014).

\section{Conclusion}

Russian financial authorities are ambivalent about the Bitcoin. Earlier, the Central Bank warned the Russians from using cryptocurrency that, within the meaning of the regulator, to be associated with white-washing and terrorist financing. However, in June, George Luntovsky, the first deputy chairman of the Central Bank said the following concerning cryptocurrency: "We are supporters of careful approach to Bitcoin, together with the Bank for International Settlements (an organization of the world's central banks), we are monitoring the situation. We cannot deny this tool, it is quite possible, it is the future".

However, supporters of Bitcoins are even among the Russian financiers. Earlier, the head of Sberbank German Gref said that Cryptocurrencies are "very interesting international experiment that breaks the paradigm of the currency issue". "They definitely do not need to be forbidden, they should be understood and can be properly adjusted," - he said.

In accordance with the published amendments to the legislation for the use of cryptocurrency, the Russian Federation Ministry of Finance proposes to establish penalties in the amount of 30 thousand to 50 thousand rubles for individuals, from 60 thousand to 100 thousand rubles - for officials, and from 500 thousand to 1 million rubles - for legal entities.

Moreover, under the penalty can even get those citizens and companies that do not use cryptocurrency, but deliberately spread information that allows one to issue monetary surrogates or transactions with them. Currently, 
it is impossible to get more information at from the Finance Ministry in this regard. The text of the bill on cryptocurrency is called "Cash Surrogates".

Previously we have discussed the possibility of a total ban for using of virtual currency in Russia and criminal penalties for non-compliance.

Thus, the current version of the bill is softer. Nevertheless, authorities still have not provided a mechanism that will help to fight against the virtual currency, and keep track of all transactions in the market. In turn, the Central Bank hastily declared that the identification of operations with cryptocurrency in the Internet and making decisions on them is not consistent with its objectives and functions.

According to analysts, the Ministry of Finance has published a bill, announcing the plans to regulate adoption of Bitcoins in Russia, but this does not mean that cryptocurrency in Russia has no future. "I do not want to say that this is nonsense, but many financial authorities understand that with proper regulation cryptocurrency offer very interesting business opportunities. At least a transaction value of cryptocurrency approaches zero. This is really a very interesting financial instrument" - said Karen Kazeryan, the analyst of the Russian Association of Electronic Communications (Pashkus, 2013).

The most "deplorable" bill, banning the full use of virtual money on the territory of Russia, will be passed by the Parliament in the spring of 2015. Arguing the need for such restrictions, deputies use the European experience, where the flow between the virtual and the real monetary systems was also decided to ban. It will not affect the electronic money (for example, Webmoney), as well as gaming currencies. It is only about paying currencies that have independent issue centers, such as, in particular, Bitcoins.

Cryptocurrencies are a new technology that requires further study; it is a tool, which still has no legislative response from the government of the Russian Federation. On October 2014 no clear rules were developed for businesses or citizens, who would like to work with cryptocurrency; there were only recommendations, such as the statement of the CBRF about virtual currency and Bitcoin in particular (Social science research network).

When conducting the study of such a phenomenon as cryptocurrency, in conclusion we would like to quote a prominent person - Russian President Vladimir Putin (at the extended meeting of the Government on January 31, 2013): "Global technological innovation, which has been already mentioned here, is a reality. New technologies are emerged right in front of our eyes. Not only new technologies, new industries are emerging! We need to fully participate in these processes, create conditions for innovation activities at home, in Russia, due to tax and budgetary measures, due to the customs tariff and antitrust regulation. Just focusing on the mass introduction of advanced technologies, in fact on a technological breakthrough, we will be able to provide the necessary economic growth".

\section{References}

Agarkin, V. V. (2011). Foreign exchange rates in the economy of modern capitalism. M.: Intern. Relationship.

Alekseev, A. M., Plešné, E. P., \& Shiryaev, Y. S. (2012). International monetary and credit relations. M: Intern. Otnosheniya.

Babina, N. V., \& Bashirova, S. V. (2012). Optimizing the use of collateral in lending. Issues of regional economy, $3(12), 15-21$.

Belov, V. A. (2010). The legal nature of non-cash payments and "non-cash". Business and banks, 52.

Berezin, M. P. (2012). Money in the modern interpretation, Business and banks, 22.

Bitcoin: An Innovative Alternative Digital Currency. Social science research network. Retrieved January 1, 2015, from http://www.papers.ssrn.com/sol3/papers.cfm?abstract_id=1817857

Bunkin, M. K., \& Semenov, A. M. (2012). The ruble is the currency in the European space. M.: Olympus Biznes.

Demidova, N. G., \& Ibragimov, L. F. (2010). On the question of restructuring the banking system of the Russian Federation. Accounting and banks, 4.

Federal Law of 10.07.2002 N 86-FZ (28.12.2013). "On the Central Bank of the Russian Federation (Bank of Russia)".

Finance Ministry intends to ban Cryptocurrency. Retrieved October 8, 2014, from http://pronedra.ru/money/ 2014/10/06/minfin-kriptoovaluta/

Larichev, V. D. (2011). The crimes committed in the area of bank lending, Money and Credit, 4. 
Melnikov, A. R. (2012). The global financial and monetary system and the instruments of monetary market. Vladivostok: DVGMA

Nakamoto, S. (2014). Bitcoin: Peer-To-Peer Electronic Cash System.

Pashkus, J. B. (2013). Money: Past and Present. St. Petersburg: Leningrad State University.

Redhed, K., \& Hughes, S. (2010). Financial Risk Management. M.: Infra.

Salmanova, I. P. (2013). Conceptual approaches methodology for assessing the financial potential of the enterprise. Nauka and education in the XXI cent collection of scientific papers on the materials of the International scientific and practical conference in 34 parts, 125-128.

Samoshkina, M. V. (2011). Features of the Russian market of mergers and acquisitions. Problems of regional economy, 6(1), 24-31.

Taran, E. M., \& Taran, M. A. (2014). Features of mortgage lending in Russia and abroad. Problems of regional economy, 19(2), 92-97.

Virtual gold standart. Forbes Journal. Retrieved March 30, 2014, from http://www.forbes.ru/tehno/internet-itelekommunikatsii / 67492-virtualnyi-zolotoi-standart

What is Cryptocurrency? Retrieved January 1, 2015, from https://7pay.in/crypto

\section{Copyrights}

Copyright for this article is retained by the author(s), with first publication rights granted to the journal.

This is an open-access article distributed under the terms and conditions of the Creative Commons Attribution license (http://creativecommons.org/licenses/by/3.0/). 